The Zodiacal Light. - "The Zodiacal Light as related to the Terrestrial Temperature Variations" is the subject of a reprint from the American Meteorological Fournal for November 1891, recently received from Mr. O. T. Sherman. In it the author endeavours to show that, when the temperature of the whole earth is considered, "the principal cause of variation is the difference in the sum of the local densities of the zodiacal light-forming matter which lies between us and the sun." Curves have been constructed to indicate five-yearly means of temperature variation from $I 790$ to $I 88_{4}$, five-yearly mean; for the zodiacal light, and the yearly auroral numbers for Europe south of the polar circle; but there are not sufficient data to permit the deduction of any very definite conclusion from them.

\section{THE ANCIENT TOMBS AND BURIAL MOUNDS} $O F J A P A N$.

$A \mathrm{~T}$ a recent meeting of the China branch of the Royal Asiatic Society at Shanghai, Prof. Hitchcock, of the Smithsonian Institute, read a paper on the ancient tombs and burial mounds of Japan, in the course of which he said that, while the form and structure of the Japanese mounds were now known, thanks to the as yet unpublished researches of his companion in many journeys in Japan, Mr. W. Gowland, their early origin was yet to be traced. It was surmised that a few at least of the Japanese burial customs were derived from China. In the course of his own travels in the north of China he had failed to discover any indications of the existence of mounds like those in Japan ; but he still expected to hear of them from some experienced traveller in the interior of that vast empire. Referring to the origin of the tombs, the lecturer said the first Emperor, who lived in the seventh century B.C., is supposed to be buried in Yamato, and the tombs of his successors are pointed out by the Imperial Household Department. The identity of the sepulchres may be questioned, but it is a fact that we can distinguish conserutive modifications of form apparently corresponding to successive periods of time.

Several distinct methods of interment have prevailed at different periods in Japan. They may be conveniently distin. guished as follows : (1) burial in artificial rock caves; $(2)$ in simple earth mounds, with or without coffins; $(3)$ in rock chambers, or dolmens; (4) in double or Imperial mounds. The lecturer then proceeded to illustrate the appearance of these different kinds of mounds by the aid of photograph slides thrown on to a screen. He showed that the double mounds were invariably protected by a wide and deep moat, sometimes by two, and consisted of two distinct mounds with a depression between them. One of these double mounds, near Sakai, according to Japanese reckoning dates from about the fourth century. The height is about Ioo feet, and the circuit of the base 1526 yards. The Emperor Kei Tai, who is reported to have lived in the sixth century, was one of the last emperors known to have been buried in a double mound. Some mounds have terraced sides, and this form is said to date from about the seventh century. Large quantities of clay cylinders were used for the purpose of preserving the terraces against the effects of the weather. When the covering of earth is removed, it is found that the stone chamber beneath, which contained the coffin, opens through passages often 40 feet and sometimes 60 feet long. The earth has in many cases been washed away from the mounds, exposing the rocks which are piled over the central chamber. According to a Japanese authority, in all the sepulchres the first order of performing the burials was the piling up of the earthen mound, leaving an underground tunnel leading from the outside to the very centre of the mound. This mound completed, the coffin, usually carved and made of stone, in which the corpse was placed, and sealed, was then introduced through the tunnel and placed in the centre of the mound, and the tunnel was then filled up with stones. The lecturer, however, said the coffins were not always introduced through the galleries, and the tunnels were certainly not filled up with stones, although their ends were probably closed with stones. He inferred from his own observations that the chambers were frequently, if not usually, built round the coffins. Stone and clay coffins had been found together in one cave, showing them to have been contemporaneous.

After showing a number of photographs of the pottery discovered in the mounds, he drew attention to a number of small clay figures representing human beings. He said it was a very ancient custom in Japan to bury the retainers of a prince standing upright around his grave. Like many other customs, this also came from China. In the time of the Japanese Emperor
Suinin (97-30 B.C.), his younger brother died, and they buried all who had been in his immediate service around his tomb alive. "For many days they died not, but wept and cried aloud. At last they died. Dogs and crows assembled and ate them. The Emperor's compassion was aroused, and he desired to change the custom. When the Empress Hibatsuhime-noMikoto died, the Mikado inquired of his officers, saying : "We know that the practice of following the dead is not good. What shall be done?' Nomi-no-Sukune then said: 'It is not good to bury living men standing, at the sepulchre of a prince, and this cannot be handed down to posterity.' He then proposed to make clay figures of men and horses, and to bury them as substitutes. The Mikado was well pleased with the plan, and ordered that henceforth the old custom should not be followed, but that clay images should be set round the sepulchre instead." Even as late as the year 646 an edict was published, forbidding the burial of living persons, and also the burial of "gold, silver brocade, diaper, or any kind of variegated thing." From this it might be inferred that the old custom of living burial was kept up, to some extent, even to the seventh century. The edict reads: "Let there be complete cessation of all such ancient practices as strangling oneself to follow the dead, or strangling others to make them follow the dead, or killing the dead man's horse, or burying treasures in the tomb for the dead man's sake, or cutting the hair, or stabbing the thigh, or wailing for the dead man's sake." The figures of clay thus introduced as substitutes for human sacrifices, and also to take the place of horses, are known as tsuchi ningio. Specimens of them are now very rare, and this fact leads to the supposition that the figures were not buried. but left exposed on the surface of the ground.

In the discussion which followed, Dr. Edkins pointed out the resemblance which existed between the stone relics found in Japan and China and in Europe, as indicating the existence of communication between distant lands in those days. It was also very interesting to note that, in the very earliest ages, men had been possessed with the idea of a future life for the soul.

\section{UNIVERSITY AND EDUCATIONAL} INTELLIGENCE.

CAMBRIDGE.-E. W. Hobson, M.A., Fellow and Lecturer of Christ's College, late Deputy Lowndean Professor, has been approved for the degree of Doctor in Science.

A decision on the subject of appointing lecturers in agricultural science will be taken by the Senate on February 25 .

A meeting for the purpose of considering the propriety of erecting in Westminster Abbey a memorial to Prof. Adams has been summoned by the Master of St. John's, and will be held in the Combination room of that College on Saturday, February 20, at 3.30 p.m.

ST. ANDrews. - At a meeting on Saturday, the I 3 th inst., of the Senatus Academicus of St. Andrews University, consisting of the Principals and Professors of the United College and St. Mary's College, St. Andrews, and University College, Dundee, it was unanimously resolved to confer the honorary degree of L.L.D. upon Prof. Michael Foster, F.R.S., and Dr. Hugo Miiller, F.R.S. The conferring of the degrees will take place in April.

\section{SOCIETIES AND ACADEMIES.} LONDON.

Royal Society, January 28.- "On certain Ternary Alloys. Part V. Determination of various Critical Curves, and their Tie-lines and Limiting Points." By C. R. Alder Wright, D.Sc., F.R.S., Lecturer on Chemistry and Physics in St. Mary's Hospital Medical School.

The author describes a number of "critical curves" obtained in accordance with the triangular system of representation proposed by Sir G. G. Stokes, whereby the composition of a given ternary mixture is represented by the position of the centre of gravity of three weights placed at the respective corners of an equilateral triangle, and respectively in the proportions of the three components of the mixture. With certain pairs of metals, e.g. lead and zinc, each will only dissolve the other to a limited extent when molten, so that a mixture of the two separates into two binary alloys, one containing chiefly lead with a little zinc, the other mainly zinc with a little lead, the exact proportion depending on the temperature of the mass. If a third metal, e.g. tin, be added to the mixture, such that this third, or 
"solvent," metal will mix in all proportions with either of the other "immiscible metals" separately, the ternary mixture proluced either forms a "real" ternary alloy, not separating into two different mixtures on standing (molten), or else an "ideal" alloy incapable of existing, and immediately separating into two different ternary mixtures; e.g. one chiefly containing lead with some of the tin and a little zinc, the other mainly consisting of zinc with the rest of the tin and a little lead. The two points representing these two mixtures lie on opposite sides of the point indicating the total mass of the three metals originally used, this third point lying somewhere on the straight line connecting the other two "conjugate points," or "tieline." By employing a series of mixtures containing gradually increasing proportions of the third "solvent" metal, two branches of a curve are gradually traced out representing the respective loci of the pairs of conjugate points; these two branches of the "critical curve" tend to meet at some point, termed the "limiting point," where the tie-lines vanish.

A large number of experiments were made to determine the conditions necessary to obtain the nearest possible approximations to the positions of truly conjugate pairs of points; former experiments having indicated that the compositions of the two alloys formed might be influenced by the relative proportions of the two immiscible metals, in such fashion that points slightly varying in position along one branch might be obtained as conjugates to a given point on the other branch under different conditions. It was found that such variations entirely dis. appeared with thorough admixture, which is more readily effected when the proportions used are such as to give rise to approximately equal quantities of the two alloys than when they are such that one alloy is formed to a much larger extent than the other. Observations with non-metallic analogous fluids (chloroform, water, glacial acetic acid) always gave sharply concordant values, thorough intermixture (by shaking vigorously in a stoppered bottle) being much more easy than with metals melted in a crucible and simply stirred vigorously.

Plotting the curves with the heavier immiscible fluid (lead, chloroform, bismuth) at the left hand corner of the base of the triangle, the lighter one (zinc, water) at the right hand corner, and the solvent fluid (tin, acetic acid) at the apex of the triangle, it was found that the tie-lines with chloroform-water-acetic acid, always sloped downwards to the left, the angle of slope continually increasing. The right hand branch of the critical curve rises to a maximum elevation, and then descends again to the limiting point, whilst the left hand branch continually ascends to that point. At the limiting point the chloroform and water are in the proportions $2 \mathrm{CHCl}_{3}, 5 \mathrm{H}_{2} \mathrm{O}$; the acetic acid present being less the higher the temperature, i.e. the critical curve for a higher temperature lying inside that for a lower one. At positions near the limiting point the mixture is extremely sensitive to temperature-variation; a few tenths of a degree will often make all the difference as to whether a single homogeneous fluid results (a "real" mixture), or two different ones, the point indicating the mixture in the first case lying just outside the critical curve, and in the second case inside it.

Analogous results were obtained with the metallic mixtures; with lead-zinc-tin mixtures, the lower ties slope to the left, the upper ones to the right, the limiting points also lying on the right and below the highest point of the critical curve; at this point the lead and zinc are nearly in the proportion $\mathrm{PbZn}_{6}$. Two points, one in the left hand branch, the other in the right, are indicated by the configurations of the tie-lines, corresponding approximately with the definite atomic compounds $\mathrm{SnPb}_{3}$ and $\mathrm{SnZn}_{4}$ (when aluminium is used instead of zinc, similar configurations are developed, corresponding with $\mathrm{SnPb}_{3}$ and $\mathrm{SnAl}_{4}$ ). When silver is employed instead of tin, all the ties slope to the ieft; irregularities of outline (bulges) are noticed, caused by the formation of definite atomic compounds, $\mathrm{AgZn}_{\overline{3}}$ and $\mathrm{Ag}_{4} \mathrm{Zn}_{5}$ : these bulges are still more pronounced when bismuth is used instead of lead (bismuth-zinc-silver curve). With both silver-leadzinc and silver-bismuth-zinc curves, the limiting points lie to the left $t$ of and below the highest point of the critical curve; with both tin-lead-zinc and tin-bismuth-zinc curves, to the right and below the highest points.

In any given curve, substitution of bismuth for zinc depresses the curve, so that the curve with lead uniformly lies outside that with bismuth. The curve for a higher temperature always lies inside that for a lower temperature, the effect of temperaturevariation being very much less marked at the lower parts of the curve, than at points lying anywhere near the limiting point.
February 4.-- "On the Thermal Conductivities of Crystals and other Bad Conductors." By Charles H. Lees, M.Sc., the Owens College, Manchester.

The author commences by referring to Kundt's discovery, that the metals stand in the same order as conductors and as to the velocity of propagation of light through them, and mentions that his experiments were originally intended to furnish data for a similar comparison for crystals, but that their object has been extended.

After some preliminary experiments, he adopted the "divided bar" method, which consists in placing a disk of the material the conductivity of which is required, between the ends of two bars of metal placed coaxially, heating one end of the combination, and observing, by means of thermo-junctions applied to the bars, the distribution of temperature along them-first, with the disk in position; second, with the bars in contact without the disk. When the conductivity of the bar is known, these observations suffice to determine that of the disk.

The ends of the bars which came in contact with the disks were amalgamated, as this was found to be the best method of securing good contacts These bars were suspended horizontally in a frame, and, by means of screws, set accurately in the required position.

The conductivity of the bar was determined by the method due to Forbes of determining the loss of hect from the surface by allowing the bar to cool and observing the rate of change of temperature, and then observing the steady distribution of temperature along the bar when heated at one end.

The author finds it to be $0^{*} 27$ C.G.S. unit, and to increase slightly with temperature.

The disks used were of the same diameter as the bar, and were of various thicknesses, in order to make the distribution of temperature throughout the bars nearly the same in each case.

The following are the results obtained. No relation of the kind found by Kundt for metals seems to hold for the crystals experimented on :-

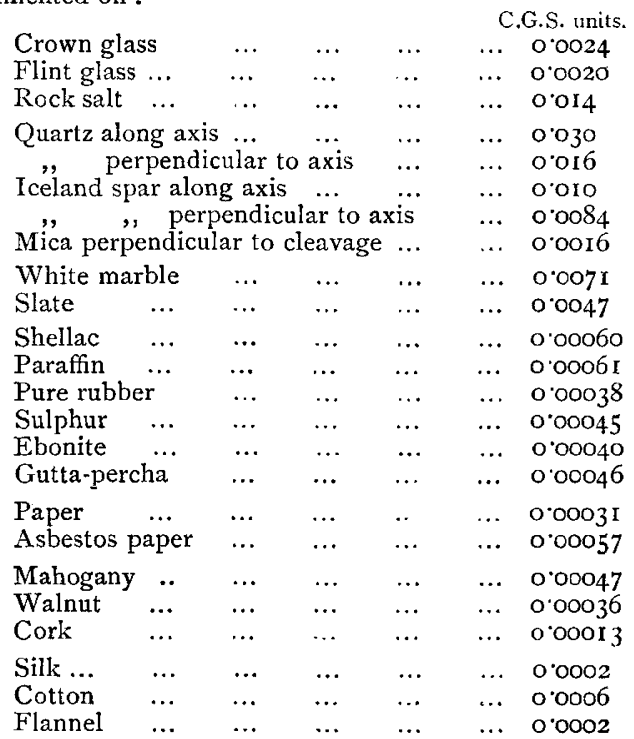

Chemical Society, January 2r.-Prcf. W. A. Tilden F.R.S., Vice-President, in the chair. - The following papers were read:-The estimation of oxygen dissolved in water, by M. A Adams. The author describes an apparatus in which the estimation of dissolved oxygen in water by Schiitzenberger's method may be carried on so as entirely to avoid loss of oxygen by diffusion. The results obtained by this method are liable to differ according to the rate at which the determinations are effected, higher results being obtained when the operations are quickly performed.-The luminosity of coal-gas flames, by V. B. Lewes. The author has quantitatively studied the actions which occur in luminous gas flames, and also those which lead to loss of luminosity in the flame of a Bunsen burner. He considers that the most accurate method of dividing a luminous hydrocarbon flame into zones, is to regard it as made up of three :(I) The inner zone, in which the temperature rises from a

No. I I 64, vol. 45] 
comparatively low point at the mouth of the burner to about $1000^{\circ} \mathrm{C}$. at the apex of the zone; in this portion of the flame various decompositions and interactions occur, which culminate in the conversion of the heavier hydrocarbons into acetylene, carbon monoxide being also produced. (2) The luminous zone, in which the temperature varies from $1000^{\circ}$ to

little over $1300^{\circ}$. The acetylene is here decomposed with liberation of carbon, which imparts luminosity to the flame. (3) The extreme outer zone, in which the combustion is practically complete. The various actions which tend to cause the loss of luminosity in a Bunsen flame may be summarized as follows :-(I) The chemical action of the atmospheric oxygen, which causes loss of luminosity by burning up the hydrocarbons before they, in their diluted condition, can afford acetylene. (2) The diluting action of the atmospheric nitrogen, which, by increasing the temperature necessary to bring about the partial decomposition of the hydrocarbons present, prevents the formation of acetylene, and so causes non-luminosity. (3) The cooling influence of the air introduced, which is able to add to the general result, although the cooling is less than the increase in temperature brought about by the oxidation due to the oxygen in the air. (4) In a normal Bunsen flame the nitrogen and oxygen are of about equal importance in bringing about nonluminosity, but if the quantity of air be increased, oxidation becomes the principal factor, and the nitrogen practically ceases to exert any influence. - The origin of flame coloration, by A. Smithells. This paper was reported in NATURE of January 28 , (p. 306). - Note on the action of dilute nitric acid on coal, by $R$. J. Friswell. If bituminous coal be treated with 49 per cent. nitric acid, a black substance is obtained which is almost completely soluble in sodium rcarbonate solution and behaves as a nitro-acid; on treating this substance further with nitric acid, a brown acid is obtained which has not yet been examined.-A pure fermentation of rnannitol and dulcitol, by P. F. Frankland and $W$. Frew. The authors have obtained an organism which sets up a fermentative decomposition, not only of mannitol, but also of dulcitol, a substance which has hitherto resisted fermenting bacteria. The products of the activity of this organism are essentially the same in the case of both sugars, consisting of ethyl alcohol, acetic acid, succinic acid, carbon dioxide, hydrogen, and varying quantities of formic acid. The decomposition may be represented by two sets of changes, viz. (a) $\mathrm{C}_{6} \mathrm{H}_{14} \mathrm{O}_{6}=$ ${ }_{2} \mathrm{C}_{2} \mathrm{H}_{6} \mathrm{O}+\mathrm{CO}_{2}+\mathrm{CH}_{3} \mathrm{O}_{2}$, and $(b) \mathrm{C}_{6} \mathrm{H}_{14} \mathrm{O}_{6}=\mathrm{C}_{4} \mathrm{H}_{6} \mathrm{O}_{4}+\mathrm{C}_{2} \mathrm{H}_{4} \mathrm{O}_{2}+$ $2 \mathrm{H}_{2}$. It appears that two molecules of the sugar are resolved in accordance with equation $(a)$ for every one decomposed according to $(b)$. The organism is termed Bacillus ethacetosuccinicus. - Synthesis of hexahydroterephthalic acid, by J. E. Mackenzie and W. H. Perkin, Jun. The sparingly soluble hexahydroterephthaliz acid of Von Baeyer is obtained by eliminating two molecules of carbon dioxide from hexamethylenetetracarboxylic acid. - The magnetic rotation of dissolved salts, by W. Ostwalci. The author considers that the values obtained by Perkin for the magnetic rotatory power of the ammonium salts of fatty acids in solution are in accord with the electrolytic dissociation theory. This theory does not lead to any numerical value or sign of the difference between the observed and calculated values of the magnetic rotation of electrolytes. In the case of haloid acids and salts the variation is positive; in the case of the oxy-acids negative. It is, therefore, not surprising that molecules with nearly zero variations are capable of existence. - The dissociation of nitrogen peroxide, by W. Ostwald. Using the data given by Cundall, the author has compared the extent to which nitrogen peroxide undergoes dis. sociation when vaporized, with that which it suffers when dissolved in chloroform. From the results he concludes that it behaves in accordance with Van 't Hoff's generalization that dissolved substances obey the same laws as gases. It appears, however, that in the gaseous state dissociation is far more advanced than in a chloroform solution.-Corydaline, by J. J. Dobbie and A. Lauder. The authors have obtained corydaline in colourless crystals melting at $134^{\circ} 5$. The results obtained on analysis do not agree with Wicke's formula, $\mathrm{C}_{38} \mathrm{H}_{19} \mathrm{NO}_{4}$, but rather with $\mathrm{C}_{22} \mathrm{H}_{28} \mathrm{NO}_{4}$. Analyses of the hydriodide, platinochloride, and methiodide of the alkaloid also give numbers agreeing with this formula. - Silver compounds of thiourea, by J. E. Reynolds. The author has obained a series of crystalline compounds of thiourea with silver nitrate, bromide, chloride, iodide, and cyanide. These substances contain one, two, or three molecules of thiourea to one of the silver salt, and readily afford silver sulphide when heated a few degrees above their melting-points.
Zoological Society, February 2.-Mr. W. T. Blanford, F.R.S., in the chair. - The Secretary read a report on the additions that had been made to the Society's Menagerie during the month of January $1892 .-\mathrm{Mr}$. W. Bateson, F.R.S., exhibited some Crabs' claws bearing supernumerary prongs. It was shown that these extra parts are really complementary (right and left) pairs of indices or pollices, according to their position of origin, and not repetitions of the two pincers of the claw, as was commonly believed.-Mr. Sclater made some remarks on the breeding of the Ground-Pigeons (Geophapes) in the Society's Gardens, and showed that the young of these Pigeons, when first hatched, were not materially different in point of development from those of the typical Pigeons, and that there was consequently no ground for separating the Geophapes from the order Columbæ on this account, as it had been recently proposed to do.-A letter was read from Prof. $R$. Kamsay Wright, inclosing some photographs of the heaps of skulls of the American Bison which are collected on the plains of the Saskatchewan, and piled up at the sidings on the Canadian Pacific Railway, awaiting transport, and which testify to the enormous number of these animals recently exterminated. - Mr. W. Bateson gave a summary of his recent observations on numerical variation in teeth. The facts given related chiefly to specimens of Quadrumana, Carnivora, Marsupials, and other orders of Mammals in the British and other Museums. The author pointed out that the ordinarily received view of homologies between teeth is based on the hypothesis that the series is composed of members each of which is either present or absent. In the light of the facts of variation, this hypothesis was shown to be untenable, and an attempt was made to arrive at a more just conception of the nature of the homology of multiple parts. - Mr. R. Lydekker described part of an upper jaw of a Sirenian Mammal from the Tertiaries of Northern Italy, containing milk-teeth. As these teeth showed a masked Selenodont structure, it was urged that the specimen indicated the descent of the Sirenia from Selenodont Artiodactyle Ungulates. It was incidentally shown that Halitherium veronense, Zigno, from the same deposits, belongs to Prorastomus, Owen.-A communication was read from the Rev. H. S. Gorham, containing descriptions of and notes on the Coleoptera collected by Mr. John Whitehead on Kina Balu, Borneo. The present communication related to the families Hispidx, Erotylidæ, Endomychidæ, Lycidæ, Lampyridæ, and others.-Another com. munication from the Rev. H. S. Gorham and Mr. C. J. Gahan gave an account of some of the Coleoptera collected by Mr. W. Bonny in the Aruwimi Valley, Central Africa.-Mr. P. L. Sclater, F.R.S., read some notes on a small collection of Mammals brought by Mr. Alfred Sharpe from Nyassaland, amongst which was a flat skin of Angas's Bush-bok (Tragelaphus angasi), a species of Antelope not hitherto recorded to occur in this district.-Mr. Sclater also gave the description of a new Antelope from Somali-land, proposed to be called Bubalis swaynii, after Captain H. G. C. Swayne, R.E., who had furnished him with the specimens on which it was based. He likewise exhibited and remarked on some other examples of Antelopes from the same country contained in Captain Swayne's collection.

Linnean Society, February 4.-Prof. Stewart, President, in the chair. - Mr. J. E. Harting exhibited Gould's coloured plate of a humming-bird (Phathornis longuemareus), of which species a pair had made their nest in the drawing-rom of $\mathrm{Mr}$. Hamilton, of Queen's Park, Trinidad. The nest was built in a palm about five feet high, standing in a tub within the room. The first egg was laid on December 27 last, the second egg on December 29, and a young bird was hatched on January $\mathbf{I} 2$. The circumstance was regarded as quite unprecedented, though Mr. D. Morris was able to quote a case which came under his own observation in Jamaica, wherein a humming-bird had built its nest on the extremity of a saddle-bar in a verandah. - Mr. Harting also exhibited some life-sized photographs of the eggcases of two species of dog-fish (Scyllium), and made some remarks on the mode of deposition and period of incubation as observed in different aquaria.-Mr. F. N. Williams read a paper on the genus Dianthus. He pointed out that Velezia, Dianthus, and Funica form a natural group of genera distinguishable from the Silene group by their seeds, which have a facial hilum and straight embryo. Velezia may be distinguished from Dianthus and Funica by having half the number of stamens. There are, however, three characters to be relied on in distinguishing these two genera: (I) the presence of a 
spicalyx of bracts ; (2) the number of nerves to the calyx ; (3) the junction of the claw with the blade of the petal. This last character was regarded as distinguishing very clearly Dianthus from Funica. In Dianthus the blade of the petal is abruptly narrowed into the claw, so that the two are distinct ; in Funica the transition is gradual. Mr. Williams was of opinion that the species of Dianthus might be arranged in three natural groups (sub-genera): (I) in which the flowers are numerous and clustered, as in "Sweet William"; (2) the largest group, in which the flowers are few and usually solitary on the branches of the stems, as in carnations ; and (3) a small group intermediate between Funica and the true pinks, and corresponding with the genus Kohlrauschia of Kunth. The number of species recognized by $\mathrm{Mr}$. Williams in this monograph amount in round numbers to 250.-A paper by Messrs. G. J. Hinde and W. M. Holmes was then read, on the Sponge remains in the Lower Tertiary strata near Oamaru, Otago, New Zealand. Near Oamaru there are beds of white, friable siliceous rock of Upper Eocene age, almost entirely composed of Sponge spicules, Diatoms, and Radiolaria, thus resembling in character the Diatom and Radiolarian ooze of the present deep seas. The Sponge remains are all detached; they belong Iargely to the Monactinellide, though Tetractinellid, Lithistid, and Hexactinellid spicules are also present. The smaller flesh spicules of these different groups are perfectly preserved, and thus enable a comparison to be made with existing Sponges, to which generically they mostly belong. In all 43 genera and I I 3 species have been recognized by their characteristic spicules. Many of the forms have not hitherto been known as fossil. The existing relatives of many of them now inhabit the Indian and Soutbern Oceans, but some are at present only known from the North Atlantic. The remains of deep water Sponges are intermingled in the deposit with others hitherto supposed to belong to moderate depths only, but in recent dredgings by H.M.S. Egeria off the south-west coast of Australia, at a depth of 3000 fathoms, there is a corresponding admixture of similar spicules.

\section{PARIS.}

Academy of Sciences, February 8.-M. d'Abbadie in the chair.-Observations on a note by M. H. Le Chatelier, on the optical measurement of high temperatures, by M. Henri Becquerel. - Silica in plants, by MM. Berthelot and G. André. An examination into the occurrence, distribution, and state, of silica in the spring-wheat plant in various stages of its growth, and into the quantity and state of the silica in the soil in which the plants were grown.--A new chart of the currents of the North Atlantic, by Prince Albert I. of Monaco. -Determination of the freezing-point of very dilute solutions: application to cane-sugar, by M. Raoult. The author describes a new method of tahing cryoscopic observations, giving readings to within I/500 of a degree. The molecular lowering of the freezing-point of water by cane-sugar is represented by a curve, which demonstrates that the author was correct in asserting that sugar gave, like other bodies, a gradual increase in its molecular lowering beyond a certain stage of dilution.-New measurement of the Perpignan base, by General Derrécagaix. The results are as follows: (I) the measured line, reduced to Delambre's base, gives for the length of this base $I 1,706.69 \mathrm{~m}$. ; (2) this length is verified by the geodesic accordance between the segments and the entire base, to an approximation of $1 / 250,000$. Hence (I) the modern measurement of the Perpignan base makes $i$ longer by $0.29 \mathrm{~m}$. than found by Delambre using Borda's measures; (2) this new length is less than that calculated from the Paris base by only $5 \mathrm{~cm}$. - New researches on the solar atmosphere, by M. H. Deslandres.-A new interpretation of Abel's theorem, by M. Sophus Lie.-On the integrals of equations of the first order which admit of only a finite number of values, by $M$. Paul Painlevé.-On a new process for the transmission of electric undulations along metallic wires, and a new arrangement of the receiver, by $M$ R. Blondlot.-Refraction of liquefied gases, by $M$. James Chappuis. The indices of refraction at zero and under their maximum vapour pressure have been found for sulphurous acid and methyl chloride. For D they are respectively $1 \cdot 3518$ and I.3533. - The rotatory power of quartz for the infra-red rays, by M. E. Carvallo. - The action of chlorine upon ruthenium : ruthenium sesquichloride and oxychloride, by M. A. Joly.-On a nitro-silicate of silver, and on the existence of a nitro-silicic acid, by MM. G. Rousseau and G. Tite.-On the decomposition of sulphurous acid by carbon at very high temperatures, by $M$.
Scheurer-Kestner. Sulphurous acid passed over charcoal at a white heat is decomposed in accordance with the equation-

$$
2 \mathrm{SO}_{2}+3 \mathrm{C}=2 \mathrm{CO}+\mathrm{CO}_{2}+2 \mathrm{~S} \text {. }
$$

- Chlorosulphide and bromosulphide of lead, by M. F. Parmentier. The chlorosulphide, obtained by a method described, is found to be $\mathrm{PbS} . \mathrm{PbCl}_{2}$. Its colour, when suspended in water, is cinnabar-red; when collected, it appears darker. The properties of the bromosulphide, $\mathrm{PbS} \mathrm{PbBr}{ }_{2}$, are similar, but it is more stable than the chlorosulphide. The existence of an iodosulphide is indicated. - Researches on sodium isopropylate, by $\mathrm{M}$. de Forcrand. - On a nitro-derivative of antipyrin, by $\mathrm{M}$. Edm. Jandrier. - On the rotatory power of diacetyltartric derivatives; reply to a note by $M$. Colson, by M. J. A. le Bel.On the minimum perceptible amount of some odours, hy $\mathrm{M}$. Jaques Passy. - The law of absorption of carbon monoxide by the blood of a living mammal, by M. N. Gréhant. - On the fauna of the fresh waters of Iceland, by MM. Jules de Guerne and Jules Richard. - On the structure of the ovule and the development of the embryonic sac of Dompte-venin (Vincetoxi. cum), by M. Gustave Chauveaud.

BOOKS, PAMPHLETS, and SERIALS RECEIVED.

Books. - Stanford's Handy Atlas of Modern Geography (Stanfird), - The London Matriculation Directory, No. xi. January $1 \varepsilon_{92}$ (Clive) - Synopsis of Non-metallic Chemistry:W. Brigg $*$ (Clive).-Pocket-book of Electrical Rules and Tables, 8th edirion: Munro and Jamieson (Griffin) - Philosophical Notes on Botanical Subjects : Dr. E. Bonavia (Eyre and Spottiswoode).The First Book of Euclid's Elements: Rev. J. B. Lock (Macmillan). Hourly Means, 1888 (Eyre and Spottiswoode).- Recollections of a Happy Life, being the Autobiography of Marianne North, 2 vols. : edited by Mrs J. A. Symonds (Macmillan).-Observations made at the Magnetical and Meteorological Observatory at Batavia, vol. xiii., IE.go (Batavia).

PAMPHLETs.-Aboriginal Skın-dressing: O. T. Mason (Washington).Ten Years' Sunshine in the British Isles, $\times 88 \mathrm{r}-90$ (Eyre and Spottiswoode). -Harmonic Analysis of Hourly Observations of Air Temperature and Pressure at British Observatories (Eyre and Spottiswoode).

SERIA I s. - Proceedings of the Royal Society of Edinburgh, vol. xviii., pp. SERIA 1 . - Proceedings of the Royal Society of Ecimburgh, vol. xvili., pp. 26x-374 (Edinburgh) - Transactions of the Burton-on. Trent Natural History and Archæological 'Societv, vol. it. (Bemrose). (Le The Taylor). - The EnYorkshire Naturalists' Union, Parts ro to I6 (Leeds, Taylor). - The Engineering Magazine, February (New York). The Geological Science, new February (K. Paui). Quarte
series, No. 30 (Churchill)

\section{CONTENTS.}

A Collection of Memoirs on Physics. By Prof. J. J.

Thomson, F.R.S.

The Formation of Beaches . . . . . . . . . 36

Egyptian History. . . . . . . . . . . . 363

Our Book Shelf :-

Hutchinson: "The Story of the Hills."-A. H. G. 364

Taylor: "The Optics of Photography and Photographic Lenses."-W.

Mitchell : "The Evolution of Life; or, Causes of Change in Animal Forms" . . . . . . . . . . $3^{64}$

Letters to the Editor:-

A Magnetic Disturbance.-G. M. Whipple . . . 364

The New Star in Auriga.-Thomas D. Anderson. 365

Nacreous Clouds.-T. W. Backhouse . . . . 365

The Cause of an Ice Age.-Sir Robert S. Ball, F.R.S.

Ice Crystals. - Bernard Hobson

A Rare British Earthworm. (Illustrated.)-Rev. Hilderic Friend

The Implications of Science.-Miss E. E. C. Jones 366

Vacuum Tubes and Electric Oscillations. - Prof.

Oliver J. Lodge, F.R.S.

The New Star in Auriga

Electrodynamic Theories and the Electromagnetic

Theory of Light. By Prof. A. Gray

On some Points in Ancient Egyptian Astronomy

II. (Illustrated.) By J. Norman Lockyer, F.R.S. Superheated Steam. By Lord Rayleigh, Sec.R.S. . Two African Explorers $\cdot \cdot \cdot \cdot \cdot$

Notes .......... 377

Our Astronomical Column:-

Photographic Magnitudes of Stars . . . . . . . . $3^{80}$

The Zodiacal Light .... . . . . . . . . $38 \mathrm{I}$

The Ancient Tombs and Burial Mounds of Japan.

By Prof. Hitchcock

University and Educational Intelligence . . . . . 38

Sor ieties and Academies . . . . . . . . . . $38 \mathrm{r}$

Books, Pamphlets, and Serials Received . . . . 384 NO. I 664 , vOJ.. 45] 